\title{
NUTRITIONAL ENRICHMENT OF KULFI BY INCORPORATING SOYA PROTEIN ISOLATES AND WHEY PROEIN CONCENTRATE
}

\author{
ANILKUMAR. S. N, RAJANNA. M, KEMPANNA. C \& PRIYANKA
}

Department of Dairy Chemistry, Dairy Science College Kalaburagi, Karnataka, India

\begin{abstract}
Soy protein is distinctive among the plant based proteins associated with isoflavones; the presence of phytochemical, with a variety of biological properties has potential benefits to human health. These proteins possess very good functional properties such as solubility, foaming, gelling, emulsifying and water binding properties. Soy Protein Isolate (SPI) is a plant extract protein, along with Whey Protein Concentrate (WPC) is good for getting better functional properties in food. The present research aims to study the impact of replacement of SNF in Kulfi mix, which is found to have a slight effect on both acidity and $\mathrm{pH}$. The findings revealed that the acidity is directly proportional to extent of replacement and inversely proportional to $\mathrm{pH}$. Further, to study the effect of replacement on sensory characteristic of Kulfi the control and treated samples were assigned to a panel of judges. The replacement had no significant effect on the colour, appearance, flavour, body and texture, as well as the overall acceptability of the product. The results clearly indicate that admixture of SPI and WPC can be effectively used to replace SNF in Kulfi to improve nutritional characteristics without affecting the quality parameters. The replacement of SNF in Kulfi mix with SPI-WPC mixture had a very slight effect on the specific gravity of Kulfi mix. The findings also revealed that, the penetration values were increased with increase in extent of replacement, in addition, showed a decrease in hardness of the sample. The melting resistance of the Kulfi increased with increase in extent of replacement of SNF with SPI - WPC mixture.

KEYWORDS: Soya Protein, Whey Protein, Kulfi, Protein Isolate \& Protein Concentrate
\end{abstract}

Received: Apr 07, 2017; Accepted: May 10, 2017; Published: May 29, 2017; Paper Id.: IJAERDJUN20174

\section{INTRODUCTION}

Soy protein is unique among the plant based proteins, because it is associated with isoflavones; these are phytochemicals with a variety of biological properties that may potentially benefit human health. Majority of soy proteins is globulins, which are insoluble in water, but soluble in dilute salt solutions. Proteins possess very good functional properties, such as solubility, foaming, gelling, emulsifying and water binding properties.

The functional properties of soy proteins, for instance solubility, foaming and emulsifying activities are affected by the physical-chemical and conformational characteristics of the protein molecules (Damodaran, 1994; Kinsella, 1976). Proteins also impart dispersibility, wettability, thickening, texturization, viscosity, gelation properties of food in addition to forming films and glasses. They are known to contribute to colour and flavour of foods. These functional properties are manifestations of hydrodynamic and surface related properties of the protein (Damodaran, 1994).

Soya isolates are used extensively as functional and nutritional ingredients such as in infant formula, health and dietetic foods (Morr, 1990). Whey proteins are generally recognized as safe (GRAS) for food product applications (Hugunin, 1987). Owing to excellent nutritional and functional properties of whey proteins, WPC has 
been significantly considered as a nutritional ingredient to improve the nutritional profile of a variety of foods (Galen et al, 1978).

Kulfi is a traditional frozen dairy product. It is very similar to ice cream in formulation, processing and composition, but it contains practically no air. The added soy protein isolate and whey protein concentrate mixture may improve the body and texture, melting quality and nutritional value of Kulfi. Indian popular frozen dairy product Kulfi, was also prepared by replacing MSNF to an extent of $80 \%$. The resultant product had higher over run, mouth feel and better accepted than the standard Kulfi (Jayaprakasha et al, 1999).

\section{MATERIALS AND METHODS}

Soy joy brand devoted to toast soy flour manufactured by Nilgiries was procured from the local market. Whole milk obtained from the Student Experimental Dairy Plant (SEDP) of the Dairy Science College, Bangalore and milk was standardized to the required fat and SNF. Amul brand cream was purchased from the market 'NANDINI' brand manufactured by Mother Dairy (A unit of K.M.F. Ltd.), was purchased from the local market. Good quality sugar was procured from the local market (FAB mall). Commercially available Sodium alginate as a stabilizer and Glycerol Mono stearate of Eagle brand as emulsifier was used. PROCON 3700 procured from Mahaan group were used during the study.

\section{Preparation of Control Kulfi}

Fresh whole milk was standardized to $5.0 \%$ fat and $8.5 \%$ SNF using cream and SMP. The standardized whole milk was heated to $65{ }^{\circ} \mathrm{C}$ for $5-10 \mathrm{~min}$. The heated milk was then homogenized by maintaining the pressure of 2500 PSI in the first stage and 500 PSI in second stage. The homogenized milk was then condensed to half its original volume in an open pan and then $13 \%$ sugar, $0.3 \%$ of stabilizer (sodium alginate) and $0.2 \%$ emulsifier (Glycerol Mono Sterate) were added and the mix was kept for ageing at $4^{\circ} \mathrm{C}$ for 6 hours, and then vanilla flavour was added to aged mix. The mix was subsequently transferred into Kulfi molds and hardened at $-22^{\circ} \mathrm{C}$ over night.

\section{Preparation of Kulfi Added with Mixture of SPI -WPC (1:1)}

Kulfi mix containing 5\% fat and $8.5 \%$ SNF was prepared using cream, SMP and admixture of SPI-WPC. The admixture of SPI-WPC is prepared by mixing SPI and WPC in equal ratio (1:1) is added (depending on the level of replacement of MSNF) only after concentrating the mix. Further procedure is same as for control (shown in flow chart). 


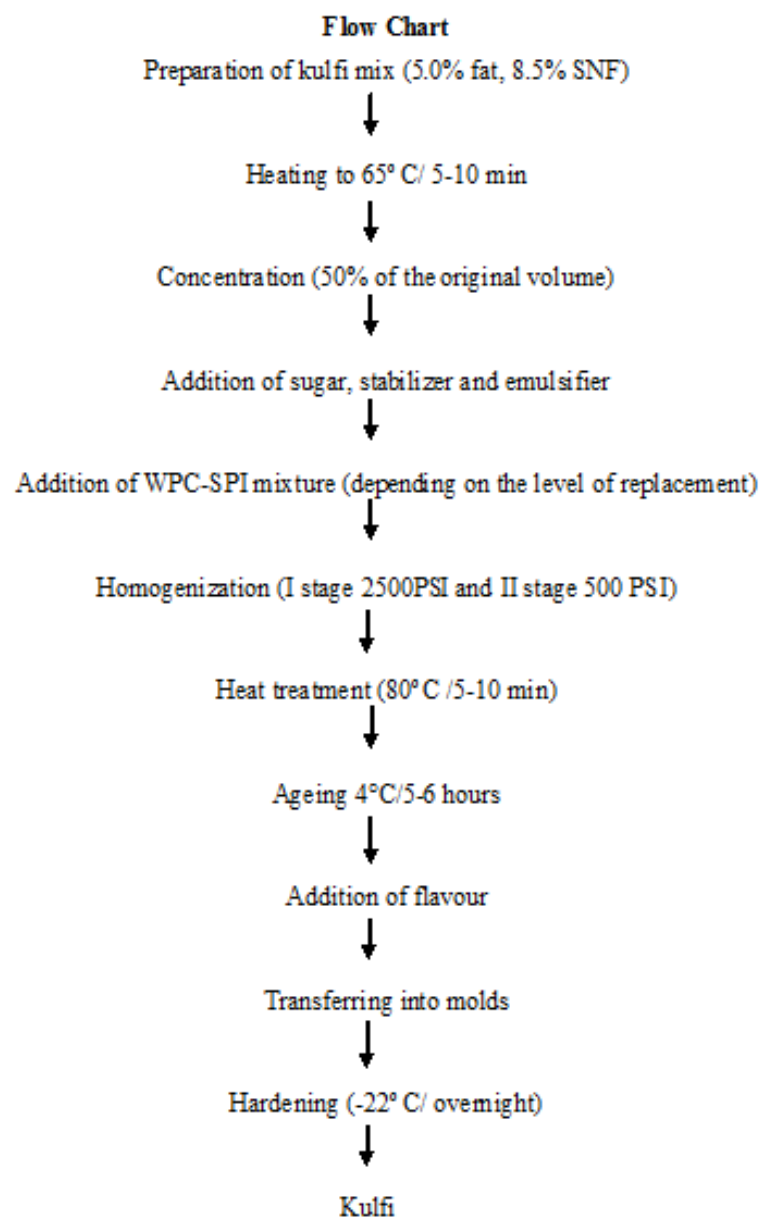

Figure 1

\section{Chemical Analysis}

Fat

Determined by Gerber method as per ISI: SP 18(Part XI) 1981

\section{Milk Solids Not Fat (MSNF)}

The MSNF content in milk was estimated by using ISI lactometer using the formula.

$\mathrm{SNF} \%=0.25 \mathrm{CLR}+0.2 \mathrm{~F}+0.48$

CLR: Corrected Lactometer Reading.

F: Fat $(\%)$

\section{Total Solids (TS)}

Total solid content of milk, yoghurt and Kulfi were determined by gravimetric method as per ISI: SP 18 (Part XI) 1981 


\section{Acidity}

It was determined by the method as per ISI: SP 18(Part XI) 1981

\section{Protein}

Protein content of yoghurt and Kulfi were determined by Micro-Kjeldal method as per ISI: SP 18(Part XI) 1981

\section{Moisture}

Moisture content was determined according to the procedure given in ISI: SP 18(Part XI) 1981

pH

The $\mathrm{pH}$ was measured by using digital $\mathrm{pH}$ meter (Elico Pvt. Ltd.).

\section{Analysis of Physical Attributes}

\section{Hardness}

The hardness of the samples was measured using a cone Pentrometer, by selecting a standard cone weighing 10.38 $\mathrm{g}$ that penetrated into products in $5 \mathrm{Sec}$ was noted, and it was expressed as millimeter of penetration. Reading was recorded at 3 different spots and average values were noted as $\mathrm{mm}$ of penetration.

\section{Specific Gravity}

Specific gravity of the sample was estimated at $27^{\circ} \mathrm{C}$ by using standard specific gravity bottle by taking distilled water as a standard liquid.

\section{Melting Resistance}

Melting resistance of ice cream was observed by weighing $10 \mathrm{~g}$ of sample on to a wire gauge, placed in a funnel over a beaker. The time taken from the sample to completely melt down and fall into a beaker at room temperature was recorded and expressed as melting resistance in minutes.

\section{Sensory Analysis}

The sensory analysis was carried out by serving controls samples with experimental samples to a panel of judges with 9 point hedonic scale score card to adjudge the quality of the product with respect to color and appearance, body and texture, flavor, and overall acceptability. The scores given by the panel of judges were then statistically analyzed. The samples were code numbered to avoid identification and bias.

\section{Statistical Analysis}

The experimental results were analyzed statistically for tests of significance by using Kruskal Wallis one way analysis of variance as per George and William (1967), and classical ANOVA as per the procedure of Sidney and John (1988)

\section{RESULTS AND DISCUSSIONS}

Soy proteins are often used in food products to improve functional characteristics besides the nutritional value. In this respect the most important property is their ability to form gels upon heating. Considering excellent nutritional and functional properties of soy and whey proteins, SPI and WPC were utilized in Kulfi in this investigation. 
Effect of Replacement of Solid Not Fat (SNF) With SPI-WPC (1:1) Mixture on Physico- Chemical Characteristics of Kulfi

The admixture of SPI and WPC (1:1 ratio) was used to replace SNF to different levels (25\% and 50\%) in Kulfi. Then, the effect of replacement on various physical chemical characteristics of Kulfi was studied

\section{Acidity and pH}

As shown in Table 1, the average acidity (\% LA) of experimental samples was 0.203 and 0.210 to $25 \%$ and $50 \%$ replacement samples respectively, as against 0.197 of the controls. The corresponding $\mathrm{pH}$ ranged from 6.48 to 6.42 for experimental samples and 6.53 for control. The results indicate that the acidity increased slightly with the increase in level of replacement of SNF with the SPI-WPC mixture and there was a corresponding decrease in the pH of Kulfi mix. However, the values of both acidity and $\mathrm{pH}$ of Kulfi mix were within the prescribed standards. Classical ANOVA was applied for analyzing the data obtained. The results indicate that there is no significant effect of replacement with respect to acidity and pH of Kulfi mix. Jayaprakasha et al (1999) observed that the replacement of SNF with WPC in Kulfi caused a slight increase in acidity and decrease in $\mathrm{pH}$. This could be ascribed to slightly higher acidity of the whey. Saritha et al (1998) have observed the similar trend when whey powder was used to replace skim milk solids in ice cream.

Table 1: Effect of Substitution of SNF with SPI-WPC (1:1) Mixture on Acidity and pH of Kulfi mix*

\begin{tabular}{|c|c|c|}
\hline $\begin{array}{c}\text { Extent of } \\
\text { Replacement }\end{array}$ & $\begin{array}{c}\text { Acidity } \\
\text { (\% LA) }\end{array}$ & $\mathbf{p H} @ \mathbf{2 5}^{\circ} \mathbf{C}$ \\
\hline control & 0.197 & 6.53 \\
\hline $25 \%$ & 0.203 & 6.48 \\
\hline $50 \%$ & 0.210 & 6.42 \\
\hline & NS & NS \\
\hline
\end{tabular}

* Average of 3 Trials NS- Non Significant

\section{Freezing Point}

The results of freezing point values of the Kulfi mix, as affected by the replacement of SNF with SPI-WPC mixture are presented in the Table 2. As the replacement of SNF with SPI-WPC mixture increased, there was a progressive increase in the depression of freezing point. The freezing point of treatment samples were $-2.68^{\circ} \mathrm{C}$ and $-2.76^{\circ} \mathrm{C}$ as against $-2.60^{\circ} \mathrm{C}$ of the control. Classical ANOVA was applied for analyzing the data obtained the results indicate that there is a quite significant effect of replacement with respect to freezing point of Kulfi mix. Similar results have been observed in the case of ice cream, when skim milk solids were replaced with WPC and sweet cream, buttermilk solids (Tirumalesha and Jayaprakasha, 1998). The substitution of SNF with WPC in Kulfi caused a depression in freezing point (Jayaprakasha et al, 1999).

\section{Melting Resistance}

The melting resistance values of Kulfi are presented in the Table 2. The increase in the replacement of SNF with the SPI-WPC mixture resulted in a gradual increase in melting resistance. The main reason for this is the good gelling properties of the soy protein as well as Whey protein. The interaction and association of soy proteins with whey proteins and their complex formation probably resulted in improved melting resistance of Kulfi sample. The values (in $\mathrm{ml} / 15 \mathrm{~min}$ ) were 16.14 and 14.40 for experimental samples as against 17.08 for the control sample. Classical ANOVA was applied for analyzing the data obtained the results indicate that there is a significant effect of replacement with respect to melting 
resistance of Kulfi.

\section{Specific Gravity}

As shown in table 2, the replacement of SNF with the SPI-WPC mixture resulted in very slight effect on the specific gravity of Kulfi mix. The values ranging from 1.10 to 1.11 from experimental sample and 1.10 for control. Classical ANOVA was applied for analyzing the data obtained the results indicate that there is no significant effect of replacement with respect to specific gravity of Kulfi mix. Saritha et al (1998) reported that very slight increase in specific gravity of ice cream was observed with increase in whey powder concentration. Reddy et al (1987) also reported similar results where a slight increase in specific gravity was noticed on whey substitution.

\section{Penetration Value}

The penetration values for Kulfi are presented in table 2. The penetration values (in $\mathrm{mm} \times 10^{-1} / 5 \mathrm{Sec}$ ) were 110.7 and 115.2 for the experimental samples as against 106 of the controls. As could be seen from the table, penetration values increased with the increase in the levels of replacement indicating decreased hardness of the sample. Classical ANOVA was applied for analyzing the data obtained the results indicate that, there is a quite significant effect of replacement with respect to penetration values of kulfi.

Table 2: Effect of Substitution of SNF with SPI-WPC (1:1) Mixture on Physical Characteristics of Kulfi*

\begin{tabular}{|l|c|c|c|c|}
\hline $\begin{array}{c}\text { Extent of } \\
\text { Replacement }\end{array}$ & $\begin{array}{c}\text { Freezing Point } \\
\left(-{ }^{\circ} \mathbf{C}\right)\end{array}$ & $\begin{array}{c}\text { Melting Resistance } \\
(\mathbf{m l} / \mathbf{1 5} \mathbf{~ m i n})\end{array}$ & Specific Gravity & $\begin{array}{c}\text { Penetration Value } \\
(\mathbf{m m ~ x ~ 1 0} / \mathbf{5 s e c})\end{array}$ \\
\hline Control & 2.60 & 17.08 & 1.10 & 106.0 \\
\hline $25 \%$ & 2.68 & 16.14 & 1.10 & 110.7 \\
\hline $50 \%$ & 2.76 & 14.40 & 1.11 & 115.2 \\
\hline CD & $\mathbf{0 . 0 2}$ & $\mathbf{0 . 1 7}$ & NS & $\mathbf{1 . 2 4}$ \\
\hline
\end{tabular}

*Average of 3 Trials

NS- Non Significant

Effect of Replacement of SNF with SPI-WPC (1:1) Mixture on the Sensory Attributes of Kulfi

The control as well as experimental Kulfi samples was served to a panel of five judges for adjudging the quality of Kulfi with respect to colour and appearance, body and texture, flavour and overall acceptability. The sensory evaluation results are presented in Table 3, in terms of average scores awarded by the judges.

\section{Color and Appearance}

The average scores with respect to colour and appearance were 8.0 and 7.6 to $25 \%$ and $50 \%$ replacement samples respectively, as against 8.2 of the controls. The scores of control and $25 \%$ replacement sample were almost same, but $50 \%$ replacement sample secured least score. Kruskal Wallis one way analysis of variance was applied for statistical analysis of the data obtained, the results indicated that the replacement of SNF with SPI-WPC mixture had no significant effect on colour and appearance of Kulfi.

\section{Body and Texture}

As shown in Table 3, the mean scores were 8.4 and 8.0 for 25 , and $50 \%$ replacement respectively as against 8.3 for control. The Kulfi prepared with 50\% replaced sample secured least scores of 8.0. From the results it is concluded that, the $25 \%$ replaced sample is better than that of control in terms of body and texture. Kruskal Wallis one way analysis of 
variance was applied for statistical analysis of the data obtained, it is apparent from the results that, the replacement of SNF with SPI-WPC mixture had no significant effect on body and texture of Kulfi.

Flavor

The scores for flavor of Kulfi are presented in the Table 3. As shown in the table, the replacement of SNF with the SPI-WPC mixture has very slight effect on the flavor of Kulfi. The scores for experimental samples were 8.0 and 7.6 to 25 $\%$ and $50 \%$ replaced respectively as against control (8.1). This shows that $25 \%$ replaced sample is on for with the control. Kruskal Wallis one way analysis of variance was applied for statistical analysis of the data obtained, the results indicated that the replacement of SNF with SPI-WPC mixture had no significant effect on the flavor of Kulfi. The slight decrease in scores could be due to release of sulphydryl groups from WPC during heating and may also due to be any flavor of SPI.

\section{Overall Acceptability}

The scores with respect to the overall acceptability of experimental samples and the control samples are presented in Table 3. The respective mean scores for the experimental samples prepared with 25 and $50 \%$ replacement levels were 8.1 and 7.6 res, as against 8.2 for the control sample. It is clear from the table that the kulfi prepared with $25 \%$ replacement of SNF with SPI-WPC mixture secured almost same score as that of the control. Kruskal Wallis one way analysis of variance was applied for statistical analysis of the data obtained, the results indicated that the replacement of SNF with SPI-WPC mixture had no significant effect on overall acceptability of Kulfi.

Table 3: Effect of Substitution of SNF with SPI-WPC (1:1) Mixture on Sensory Attributes of Kulfi*

\begin{tabular}{|l|c|c|c|c|}
\hline Extent of Replacement & $\begin{array}{c}\text { Colour and } \\
\text { Appearance }\end{array}$ & $\begin{array}{c}\text { Body and } \\
\text { Texture }\end{array}$ & Flavour & Overall Acceptability \\
\hline control & 8.2 & 8.3 & 8.1 & 8.2 \\
\hline $25 \%$ & 8.0 & 8.4 & 8.0 & 8.1 \\
\hline $50 \%$ & 7.6 & 8.0 & 7.6 & 7.6 \\
\hline & NS & NS & NS & NS \\
\hline
\end{tabular}

*Average of 3 Trials

NS- Non Significant

\section{CONCLUSIONS}

The mixture of the SPI-WPC was incorporated in Kulfi to study the effect of physical-chemical and sensory characteristics of Kulfi. The replacement of SNF with SPI-WPC mixture found to have a slight effect on both pH and acidity of Kulfi mix. As the level of replacement increases the acidity of the mix also increased and there was a corresponding decrease in $\mathrm{pH}$. The freezing point depression of the Kulfi mix increased with increase in extent of replacement of SNF with SPI-WPC mixture. The replacement of SNF in Kulfi mix with SPI-WPC mixture had a very slight effect on the specific gravity of Kulfi mix. The penetration values were increased with increase in extent of replacement showed a decrease in hardness of the sample. The melting resistance of the Kulfi increased with increase in extent of replacement of SNF with SPI - WPC mixture. The effect of replacement on sensory characteristics of the Kulfi was studied. The replacement had no significant effect on the colour and appearance, flavour, body and texture as well as the overall acceptability of the product. 


\section{REFERENCES}

1. *Damodaran, S., 1994, Structure function relationship of food proteins. In: Hetliarachchy, N.S. and Ziegler, G.R., Ed. Protein Functionality in Food Systems. Marcel Dekker, New York, 1-37.

2. George W. Snedecor and William G. Cochrna, 1967., Statistical methods. Sixth edition, Oxford and IBH, New York.

3. *Hugunin, A.G., 1987, Application of UF whey protein: developing new markets in trends in whey utilization. Int Dairy Fed Brussels, Belgium, p135

4. IS:PS:18., 1981, ISI hand book of food analysis, part XI dairy products. Indian Standards Institution, Manak Bhavan, New Delhi

5. Jayaprakasha, H.M., Sathyanarayana, H., and Shobha Bhat., 1999, Effect of whey protein concentrate on the quality attributes of Kulfi. Indian J. Dairy \& Biosciences., 10: 64-69.

6. Jelen, P., Buchhein, W. and Peters. K.H., 1978, The use of chakka whey and its Components in human Foods. Food Technol., 17:23-28.

7. Kinsella, J.E., 1976, Functional properties of proteins in foods. A survey, Crit. Rev. Food Sci. Nutri., 17: $219-251$.

8. Morr, C.V., 1990, Functionality of oilseed and legume protein. Jr. Am. Oil Chem. Soc., 67 (5): 265-271.

9. Reddy, V.P., Ranganadham, N., Reddy, C.R. and Karnani, B.T., 1987, studies on the value of chhana whey solids in the preparation of Ice cream in partial replacement of MSNF of mix. J. Dairy Sci., 40: 128-131

10. Saritha, M., Ramanjaneyulu, G. and H.M. Jayaprakasha, 1998, Effect of whey powder on physico- chemical and sensory attributes of Ice cream. Indian J. Dairy \& Biosciences., 9:31-36.

11. Sidney Siegel and N. John Castellan, Jr., 1988, nonparametric tests for the behavioral sciences. Second edition, Mcgraw-hill. New York.

12. Tirumalesha, A., H.M. Jayaprakasha, 1998, Effect of admixture of spray dried whey protein concentrate and Butter milk powder on physico- chemical and sensory attributes of Ice cream. Indian J. Dairy Sci., 51(1):13-19 